\title{
The effect of polypropylene, steel, and macro synthetic fibers on mechanical behavior of cementitious composites
}

\author{
Ayşe Elif Özsoy Özbay® ${ }^{1}$, Orhan Erkek $\mathbb{D}^{2}$, Seyit Çeribaş*(i) 1 \\ 1 Civil Engineering Department, Maltepe University, İstanbul (Turkey), ayseelifozsoyozbay@ maltepe.edu.tr; sey- \\ itceribasi@gmail.com \\ 2 Structures and Earthquake Engineering Department, Maltepe University, İstanbul (Turkey), orhan_erkek@hot- \\ mail.com \\ *Correspondence: seyitceribasi@gmail.com
}

Received: 18.03.2021; Accepted: 02.11.2021; Published: 31.12.2021

Citation: Özbay, A., Erkek, O. and Ceribasi, S. (2021). Manuscript title. Revista de la Construcción. Journal of Construction, 20(3), 591-601. https://doi.org/10.7764/RDLC.20.3.591.

\begin{abstract}
Incorporation of fibers in concrete has been an efficient technique to prevent crack propagation, thus improving ductility, durability, toughness and strength of concrete. In this context, a comprehensive experimental study has been conducted concerning the compressive and flexural strength of fiber reinforced concrete, through preparing nine concrete batches with polypropylene fibers, steel fibers and macro synthetic fibers; and the hybrid forms combining polypropylene (PP) and steel, polypropylene and macro synthetic fibers. Fiber inclusion in concrete caused slight variations in compressive strength. However, the flexural strength for all sample sets was significantly increased. The highest values of strength increase relative to control concrete were $60.67 \%, 42.45 \%$ and $27.05 \%$ incorporating steel, polypropylene and macro synthetic fibers, respectively. It was also noted that the higher aspect ratio of steel fibers resulted with better flexural performance, among the steel fiber reinforced concrete samples. Hybrid forms of polypropylene-steel and polypropylene -macro synthetic fibers achieved the highest flexural strength compared with samples including single type of fiber. In blended groups, utilization of polypropylene fibers with steel fibers and with macro synthetic fibers resulted with $69.81 \%$ and $78.99 \%$ of increase in flexural strength relative to control specimens, respectively.
\end{abstract}

Keywords: polypropylene fibers; steel fibers; synthetic fibers; concrete; mechanical properties

\section{Introduction}

The efforts to enhance the engineering properties of concrete as one of the most widely used construction material have given rise to the research interest on advances in performance of concrete. Those research attempts mainly focused on new methods to achieve improvements in tensile and flexural strengths, ductility and durability while conforming to the environmental requirements for reduction of carbon emissions due to huge amount of concrete production. The rapid growth in construction industry in the last decades has given rise to advances in concrete technology mainly focusing on new strategies for sustainable cementitious composites in order to achieve reduction in the environmental impacts as well as improvements in mechanical properties. The increasing demand for concrete as a versatile and affordable construction material leads to new research fields to enhance the engineering properties including strength and durability, while recent research interest is directed towards improving sustainable alternatives to partially supplement cement in concrete in order to reduce carbon emissions due to cement production (Mehta, 2001; Malhotra, 2002; Lee \& Lee, 2013; Nath \& Sarker, 2014; Karapinar \& Biricik, 2020). 
Low tensile strength, ductility, and the poor resistance against crack formation are the main shortcomings that affect the performance of concrete and restrict its efficient use. Incorporation of fibers into concrete has been utilized to avoid crack propagation and to enhance ductility, toughness and strength properties of concrete. Moreover, the protection of steel components of reinforced concrete structures has been an important subject of similar researches. Recently, Chousidis, Zacharopoulou, and Batis (2020) investigated corrosion safety of reinforcement steel by using solid waste materials.

Fiber reinforced concrete (FRC) is a cement-based composite material which is capable of achieving higher tensile strength and ductility through the use of short and discrete fibers generally produced from steel, polymers, natural materials or glass and distributed over the concrete volume. The use of steel fibers in concrete has gained much attention due to its beneficial effects on flexural strength, strain capacity and durability of traditional concrete (Rapoport, Aldea, Shah, Ankenman \& Karr, 2001; Grzybowski \& Shah, 1990; Noushini, Samali \& Vessalas, 2014). The crack bridging mechanism exhibited by the inclusion of steel fibers in concrete matrix leads to the stress redistribution which eventually reduces the crack tip opening and restrains widening of cracks (Banthia \& Trottier, 1995; Tiberti, Minelli \& Plizzari, 2015; Balendran, Zhou, Nadeem \& Leung, 2002). The extent of the benefits that are acquired through the use of steel fiber mainly depends on the type, content, geometry and the aspect ratio of fibers as well as the concrete mix design. The experimental studies on the effect of steel fiber content reveal the increase in fiber content leads to significant improvements in strain capacity and tensile strength whereas the compressive strength and elastic modulus are slightly altered (Yoo, Yoon \& Banthia, 2015; Sahin \& Koksal, 2011). The flexural strength of concrete with steel fibers is considerably improved with the increase of fiber aspect ratio. However, the workability of concrete mixture is reduced especially for higher values of aspect ratio (Yazici, Inan \& Tabak, 2007; Abbass, Khan \& Mourad, 2018).

Incorporation of synthetic fibers, i.e. polypropylene (PP), polyvinyl alcohol (PVA), polyethylene (PE), nylon, into cementbased materials has also been found to contribute to durability and mechanical properties of concrete as a cost-efficient alternative material (Kavitha, Venkatesan, Avudaiappan \& Flores, 2020). Polypropylene, as a thermoplastic polymer based material, is a widely used fiber type in cementitious composites which favors post-cracking tensile and flexural behavior of cement and thereby promotes the concrete toughness substantially (Sun \& Xu, 2009). The research findings reveal that polyprolylenefiber reinforced concrete performs better in compressive, tensile and flexural strengths by higher volume of fibers (Banthia \& Gupta, 2006; Kayali, Haque \& Zhu, 2003). The use of polypropylene fibers has been reported to reduce permeability, shrinkage and expansion of concrete which significantly improves durability as well (Kakooei, Akil, Jamshidi \& Rouhi., 2012). This reduction has been attributed to the bridging mechanism in concrete matrix which reduces crack propagation. Among the various applications in the field, macro-synthetic fibers have emerged in the past decades due to their lower cost in comparison to other high-performance fibers. In a recent study, macro synthetic and multifilament polypropylene fibers with varying volume fractions have been utilized in order to investigate their effects on crack distribution and tensile stress-strain behavior in cement composites (Mobasher, Dey, Bauchmoyer, Mehere \& Schaef, 2019). The results revealed that multifilament microfibers performed better in terms of first crack and ultimate values of strength, and toughness comparing the fiber types at $4 \%$ content, while the performance of the macrofibers was slightly higher at lower fiber contents.

A promising technique to enhance the flexural behavior of cementitious composites is to blend micro and macro fibers in cement matrix (Kim, Park, Ryu \& Koh, 2011). Hybrid form of fibers contribute to the mechanical performance and ductility of cementitious materials with normal strength considerably when compared with fiber reinforced concrete with single fiber type (Qian \& Stroeven, 2000; Yao, Li \& Wu, 2003; Banthia \& Nandakumar, 2003). In a previous research conducted by Kim, Park, Ryu, and Koh (2011), the effects of hybrid incorporation of fibers in ultrahigh performance concrete were investigated and it was concluded that modulus of rupture, deflection capacity and energy absorption capacity have been improved through blending high strength steel macro and micro fibers in concrete matrix in comparison with the inclusion of monotype microfibers. Moreover, a study conducted by Akçay (2012) was focused on examining the fracture properties of hybrid fiber concrete through blending short and long fibers in concrete matrix and testing under uniaxial loading. It was concluded that the increase in amount of thin short fibers controlled the formation of multiple cracks before the peak, while the large fibers could improve the bridging effect for localized macrocracks. Therefore, the use of hybrid fibers plays a key role in improving the mechanical performance of fiber reinforced concrete besides the effects of aspect ratio, orientation and distribution of fibers in concrete matrix. 
A detailed review of the literature reveals that a great number of studies have been performed so far on the use of fiber reinforced concrete and the effects of fiber incorporation on the overall performance of cementitious composites. Ongoing research on fiber reinforced concrete mainly concerns the effects of fiber content, shape and size as well as the type of fibers on strength and durability of concrete. Thus, further studies are required to provide in-depth information on the tailored mechanical properties of fiber reinforced concrete. With this motivation, the main objective of this study is to investigate mechanical performance of fibrous concrete produced with polypropylene, steel and macro synthetic fibers and their dual combinations in hybrid forms incorporated in concrete. In line with this, ten specimen sets of fiber reinforced concrete were produced utilizing (i) polypropylene fibers with two different lengths, (ii) two different types of macro synthetic fibers, (iii) steel fibers having two different aspect ratios and (iv) the blended forms prepared using polypropylene fibers with steel and macro synthetic fibers along with the control specimens and tested for compressive and flexural strengths. Although there are a great number of studies on this subject, this paper presents a comprehensive experimental work on the tailored mechanical properties of fiber reinforced concrete considering the stated fiber parameters, fiber type as well as their blended forms incorporated in concrete, thereby providing a comparative assessment of each configuration and their benefits in strengthening the performance of ordinary concrete as a construction material.

\section{Materials and methods}

\subsection{Materials}

The cement used in the experimental study was Portland cement (PC 42.5 D) and slag cement (C-PC 42.5) as the binder complying with Turkish Standard TS EN 197-1 (2002). The concrete mixture was proportioned with composition of two aggregate types with size fractions as 5-12 mm (No.1) and 12-22 mm (No.2) meeting the requirements of TS 706 EN 12620 (2003); and natural sand as the fine aggregate. A commercial admixture (ULTRATON 940) having a high water reduction efficiency was utilized as the superplasticizer in order to achieve the desired workability for all concrete mixtures. Table 1 shows the mix proportions of the materials that were used to produce the control concrete as well as the testing sets prepared with fiber inclusion in the testing program.

Table 1. Mix proportions for concrete.

\begin{tabular}{lc}
\hline Material & $\begin{array}{c}\text { Quantity } \\
\left(\mathrm{kg} / \mathrm{m}^{3}\right)\end{array}$ \\
\hline Aggregate No.1 & 570 \\
Aggregate No.2 & 550 \\
Sand & 400 \\
Crushed stone & 315 \\
Water & 150 \\
Slag cement & 50 \\
PC cement & 290 \\
Superplasticizer & 4.42 \\
\hline
\end{tabular}

In order to investigate the effect of fiber types and the hybrid forms of fibers on the compressive and flexural behaviors, ten different concrete mixes were produced. The specimens included polypropylene fibers with two different lengths, steel fibers with three different aspect ratios, two testing sets with different macro synthetic fibers, and the control concrete specimen. Types of fibers utilized in this study are illustrated in Figure 1.

The hooked-end steel fibers used in the experimental study were Type 1 cold drawn steel wires manufactured according to ASTM A820/A820M-04 (2015). The general properties of steel fibers with different diameters and length are given in Table 2. Regarding the macro synthetic fibers, Enduro Prime (EP) was produced from sinusoidal shaped polyolefin fibers with smooth surface and Macromesh (MM) was produced from twisted bundle polypropylene fibers having a rough texture to avoid crack formation due to shrinkage. Moreover, two different lengths of polypropylene micro-fibers (12 and $19 \mathrm{~mm}$ ) were incorporated in the concrete and labeled as BF12 and BF19 among the testing groups. Table 3 describes the mechanical and physical properties of polypropylene and macro fibers used in the experimental study. 


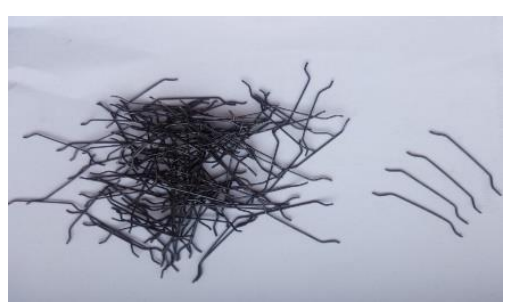

(a)

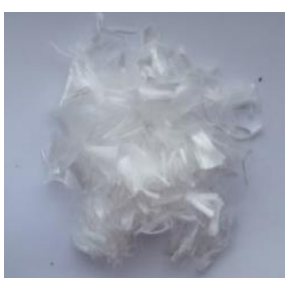

(d)

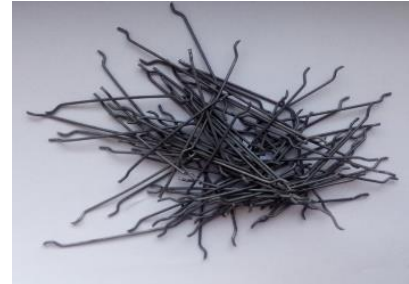

(b)

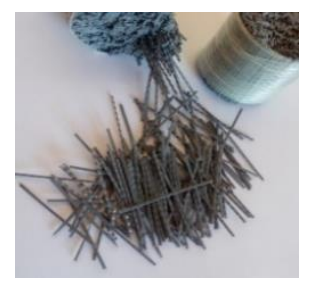

(f)

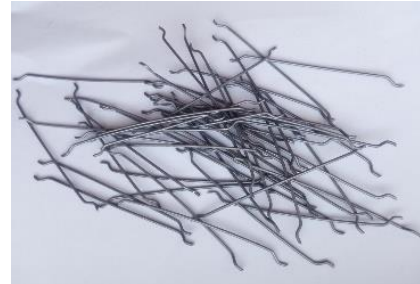

(c)

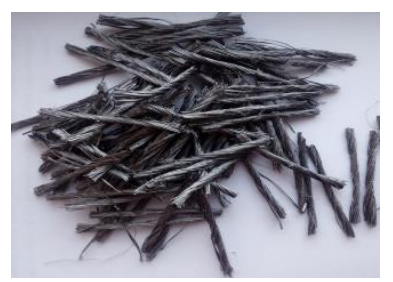

$(\mathrm{g})$

Figure 1. Types of fibers: (a) steel fiber (HE0735); (b) steel fiber (HE1050); (c) steel fiber (HE0960); (d) polypropylene fiber (BF12); (e) polypropylene fiber (BF19); (f) macro synthetic fiber (EP); (g) macro synthetic fiber (MM).

Table 2. Properties of steel fibers.

\begin{tabular}{lccc}
\hline Steel Fiber & HE0735 & HE1050 & HE0960 \\
\hline Length $(\mathrm{mm})$ & 35 & 50 & 60 \\
Diameter $(\mathrm{mm})$ & 0.70 & 1.00 & 0.90 \\
Tensile strength (MPa) & 1400 & 1200 & 1100 \\
Aspect ratio (l/d) & 50 & 50 & 66 \\
\hline
\end{tabular}

Table 3. General properties of polypropylene and macro synthetic fibers.

\begin{tabular}{lcccc}
\hline & \multicolumn{2}{c}{ Polypropylene fibers } & \multicolumn{2}{c}{ Macro synthetic fibers } \\
\cline { 2 - 5 } & BF12 & BF19 & EP & MM \\
\hline Length (mm) & $12 \mathrm{~mm}$ & $19 \mathrm{~mm}$ & $60 \mathrm{~mm}$ & $54 \mathrm{~mm}$ \\
Diameter & $18 \mu \mathrm{m}-20 \mu \mathrm{m}$ & $18 \mu \mathrm{m}-20 \mu \mathrm{m}$ & - & - \\
Number of fibers per kg & - & - & $>140000$ & $>200000$ \\
Density $\left(\mathrm{gr} / \mathrm{cm}^{3}\right)$ & 0.91 & 0.91 & 0.91 & 0.91 \\
Tensile strength (MPa) & $450-700$ & $450-700$ & $600-800$ & $550-750$ \\
Modulus of elasticity (MPa) & $3000-3500$ & $3000-3500$ & - & - \\
Melting point $\left({ }^{\circ} \mathrm{C}\right)$ & $162{ }^{\circ} \mathrm{C}$ & $162{ }^{\circ} \mathrm{C}$ & $160{ }^{\circ} \mathrm{C}$ & $160-170{ }^{\circ} \mathrm{C}$ \\
\hline
\end{tabular}

\subsection{Preparation of specimens}

The mixtures were prepared in the concrete mixer according to the proportions for each batch given in Table 4. The testing batches No.1 and No.2 were designated by adding polypropylene fibers of varying length as $12 \mathrm{~mm}$ and $19 \mathrm{~mm}$ (BF12 and BF19) in the mixture, respectively. The hooked-end steel fibers (HE0735, HE1050 and HE0960) used in batch groups No.3, 4 and 5 had varying diameter and length concerning two different (1/d) ratios. Additionally, two series of concrete mixture were prepared with inclusion of different macro synthetic fibers (EP and MM) regarding the test groups No.6 and 7. Finally, to investigate the blending effect of PP fibers with macro synthetic and steel fibers on compressive and flexural behavior of fiber reinforced concrete, two mix designs were prepared in hybrid form, denoted as Batch No. 8 and 9. as given in Table 4. Volume fractions of fibers were kept constant for the sample groups including steel and macro synthetic fibers. 
Table 4. Testing groups in the experimental program.

\begin{tabular}{lllcc}
\hline Batch No. & Fiber type & Notation & Volume fraction & Batch weight $\left(\mathrm{kg} / \mathrm{m}^{3}\right)$ \\
\hline 1 & \multirow{2}{*}{ Polypropylene } & BF12 & $0.07 \%$ & 0.6 \\
2 & BF19 & $0.10 \%$ & 0.6 \\
3 & HE0735 & $0.25 \%$ & 20 \\
4 & Steel & HE1050 & $0.25 \%$ & 20 \\
5 & & HE0960 & $0.25 \%$ & 20 \\
6 & \multirow{2}{*}{ Macro synthetic } & EP & $0.45 \%$ & 4 \\
7 & & MM & $0.45 \%$ & 4 \\
8 & \multirow{2}{*}{ Hybrid } & EP and BF12 & $0.45 \%-0.07 \%$ & $4-0.6$ \\
9 & & HE0960 and BF12 & $0.25 \%-0.07 \%$ & $20-0.6$ \\
\hline
\end{tabular}

The composition of concrete mixtures for all batches prepared by utilizing the prescribed amounts of aggregates, sand and superplasticizer; and water/cement ratio of 0.44 are given in Table 1. During the specimen preparation process, cement and sand were initially dry-mixed for $60 \mathrm{~s}$ and blended with the aggregates, water and the superplasticizer with a mixing time of $5 \mathrm{~min}$. Acquiring the appropriate workability of fresh mixture to ensure uniform distribution of fibers, the specified fiber content regarding the testing sets were added in the concrete mix and blended carefully. Ultimately, the fresh mixture of fiber reinforced concrete for each testing set was cast into cubic molds with dimensions of 150x150x150 mm for the compression test; and prismatic molds with dimensions of 150x150x500 mm were used for the preparation of flexural specimens. The specimens were demolded after $24 \mathrm{~h}$ and were cured in water tanks at a temperature of $20{ }^{\circ} \mathrm{C}$ until the age of testing for determination at 28-day strength.

\subsection{Testing procedure}

The compressive tests on 150x150x150 mm cubic specimens were conducted by the testing machine (UTEST) under a load control at a rate of $0.6 \mathrm{MPa} / \mathrm{s}$. 28 day compressive strengths of the specimens were obtained following the guidelines stated in TS EN 12390-3 (2003). Moreover, three-point bending tests were performed on prisms having dimensions of 150x150x500 mm in order to examine the flexural behavior of fiber reinforced concrete specimens. According to the testing procedures specified in TS EN 12390-5 (2002) and TS 10515 (1992), 28 day flexural specimens were loaded at the mid-span with a rate of $0.05 \mathrm{MPa} / \mathrm{s}$ as illustrated in Figure 2. The flexural strength of each sample subjected to three-point bending was determined as:

$$
\sigma=\frac{3}{2} x \frac{P x L}{b x h^{2}}
$$

In Eq. (1), $\mathrm{P}$ is the ultimate load, $\mathrm{L}, \mathrm{b}$ and $\mathrm{h}$ are the span, width and depth of the specimen, respectively. 


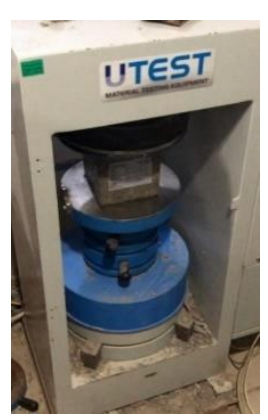

(a)

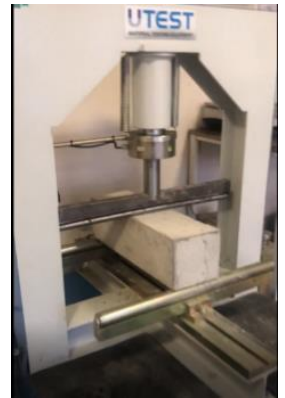

(b)

Figure 2. Experimental setup for (a) compressive test on 150x150x150 mm cubic specimens and (b) three-point bending test on 150x150x500 mm prismatic specimens.

\section{Results and discussion}

\subsection{Effect of the fiber parameters on the compressive strengths}

The results of the 28 day compressive and flexural strength tests conducted on fiber reinforced concrete specimens containing PP, steel, macro synthetic fibers and the blended forms of PP fibers with steel and macro synthetic fibers, including the control concrete are given in Table 5. Considering the entire testing groups, fiber inclusion in concrete was found to cause slight reduction in compressive strength for the mixtures with PP fibers and macro synthetic fibers whereas the compressive strengths of mixtures containing steel fibers were slightly higher than the results of the control specimens.

Table 5. Mechanical properties of fiber reinforced concrete mixtures.

\begin{tabular}{|c|c|c|c|c|c|c|c|c|}
\hline \multirow[b]{2}{*}{ Fiber type } & \multirow[b]{2}{*}{ Mix ID } & \multirow[b]{2}{*}{$\mathrm{V}_{\mathrm{f}}(\%)$} & \multicolumn{3}{|c|}{ Compressive strength } & \multicolumn{3}{|c|}{ Flexural strength } \\
\hline & & & $\begin{array}{c}\text { Control } \\
(\mathrm{MPa})\end{array}$ & $\begin{array}{l}\text { Compressive } \\
\text { strength (MPa) }\end{array}$ & $\%$ Increase & $\begin{array}{c}\text { Control } \\
(\mathrm{MPa})\end{array}$ & $\begin{array}{c}\text { Flexural } \\
\text { strength } \\
\text { (MPa) }\end{array}$ & $\%$ Increase \\
\hline \multirow{2}{*}{ PP } & $\mathrm{BF} 12$ & 0.07 & 46.60 & 46.20 & -0.86 & 4.17 & 5.24 & 25.66 \\
\hline & BF19 & 0.10 & 46.60 & 45.20 & -3.00 & 4.17 & 5.94 & 42.45 \\
\hline \multirow{3}{*}{ Steel } & HE0735 & 0.25 & 46.60 & 46.80 & 0.43 & 4.17 & 5.50 & 31.89 \\
\hline & HE1050 & 0.25 & 46.60 & 47.00 & 0.86 & 4.17 & 5.62 & 34.77 \\
\hline & HE0960 & 0.25 & 46.60 & 47.50 & 1.93 & 4.17 & 6.70 & 60.67 \\
\hline \multirow{2}{*}{ Macro synthetic } & $\mathrm{EP}$ & 0.45 & 40.30 & 39.50 & -1.99 & 4.14 & 5.26 & 27.05 \\
\hline & MM & 0.45 & 40.30 & 38.50 & -4.47 & 4.14 & 4.96 & 19.81 \\
\hline Macro synthetic-PP & EP-BF12 & $0.45-0.07$ & 40.30 & 39.10 & -2.98 & 4.14 & 7.03 & 69.81 \\
\hline Steel-PP & HE0960-BF12 & $0.25-0.07$ & 40.30 & 40.90 & 1.49 & 4.14 & 7.41 & 78.99 \\
\hline
\end{tabular}

As observed from the results concerning PP fiber reinforced specimens presented in Figure 3, BF12 and BF19 having volume fractions of 0.07 and 0.10 , compressive strength results decreased by $0.86 \%$ and $3 \%$, respectively. Similarly, compressive strengths of EP and MM specimens containing macro synthetic fibers of 0.45 volume fractions were also reduced by $2 \%$ and $4.47 \%$, respectively. Comparing the results of mixtures with PP and macro synthetic fibers, the strength reduction was more significant for the specimens having macro synthetic fibers, which might be attributed to higher volume fraction of macro fibers $(0.45 \%)$ than PP fibers $(0.07 \%$ and $0.10 \%)$. Among all designated specimen groups, the samples containing steel fibers, HE0735, HE1050 and HE0960 (with fiber lengths of $35 \mathrm{~mm}, 50 \mathrm{~mm}$ and $60 \mathrm{~mm}$ ), could achieve higher compressive strengths for which percent increase values with respect to the control specimens were found to be $0.43,0.86$ and 1.93 , respectively. This mild increase in compressive strength of specimens might be due to the increased aspect ratio of steel fibers leading to an improved crack arresting behavior (Abbass, Khan \& Mourad, 2018). The final two testing groups, EP-BF12 and HE0960-BF12, were the blended forms of PP fibers with steel and macro synthetic fibers, respectively. It was observed that the blending of macro fibers with PP fibers in concrete mixtures (EP-BF12) resulted in a slight decrease in strength as $2.98 \%$ 
whereas incorporating hybrid form of PP fibers with steel fibers resulted in slightly increased compressive strength (1.49\%) according to control concrete specimens.

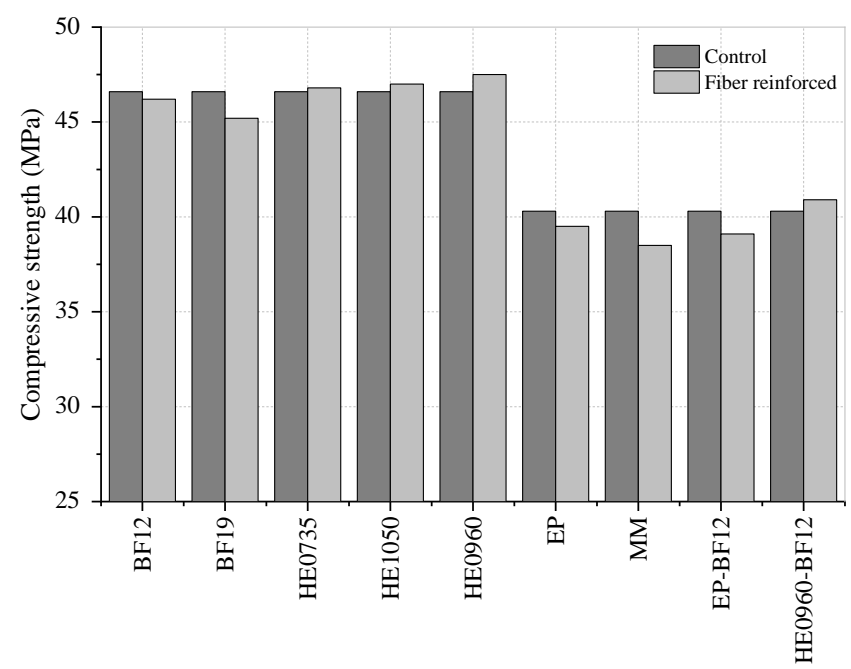

Figure 3. 28 Day compressive strength results.

Inspecting the overall results of compression tests on the fiber reinforced concrete samples, it was observed that incorporation of fibers regardless of the fiber type did not cause remarkable changes in strength with respect to the plain concrete specimens. Some of the previous studies on the use of fiber reinforced concrete also stated that utilization of steel fibers in concrete resulted with an increase in compressive strength to some extent, while the effect of synthetic fibers on compressive strength was not significant (Bolat, Şimşek, Çullu, Durmuş \& Can, 2014; Neville, 2011; Guerini, Conforti \& Plizzari, 2018). On the other hand, inclusion of fibers was reported to contribute to improvements in flexural behavior and ductility of concrete in most of the cases for fiber reinforced concretes. Accordingly, here in this study, fiber incorporation induced slight improvements in compressive strength, while the increase in flexural strengths of fiber reinforced specimens were clearly observed for all combinations.

\subsection{Effect of the fibers on the flexural strengths}

The three-point bending test results conducted on 150x150x500 mm prismatic specimens for the entire testing groups reveals that the flexural strengths of fiber reinforced concrete specimens were improved remarkably relative to the samples without fibers. The extent of improvements in flexural strength mainly depends on the size, shape, aspect ratio and volume fraction of fibers as well as the fiber type and utilization of different types of fibers in concrete mixture. Figure 4 illustrates the 28-day flexural strength results obtained for fiber reinforced concrete samples and the control specimens without fibers.

The series prepared by PP fibers, BF12 and BF19 with volume fractions of $0.07 \%$ and $0.10 \%$, have reached flexural strength values of 5.24 MPa and 5.94 MPa, respectively. It was noted that the use of longer fibers $(19 \mathrm{~mm})$ and higher volume fraction $(0.10 \%)$ has remarkably increased the flexural strength of the specimens by $42.45 \%$ whereas the specimens with fiber length of $12 \mathrm{~mm}$ having a $0.07 \%$ of volume fraction has attained $25.66 \%$ of increase in strength. This result clearly implied that longer fibers incorporated into concrete considerably enhanced the bonding with cement matrix preventing the crack propagation through bridging of fibers, which was also reported by Banthia and Gupta (2006).

Moreover, consistent with results of this study, the previous research findings revealed that the flexural strength of fiber reinforced concrete was enhanced with the increase in volume fractions lower than $0.5 \%$ due to crack bridging mechanism (Kayali, Haque \& Zhu, 2003; Kakooei, Akil, Jamshidi \& Rouhi, 2012). 


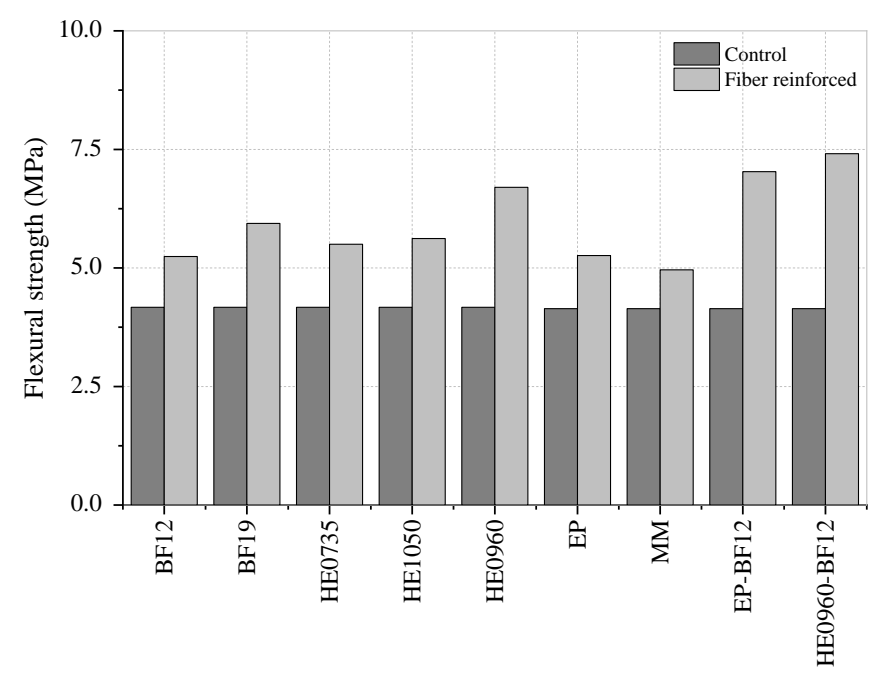

Figure 4. 28 Day flexural strength results.

Considering the test results of the steel fiber reinforced concrete samples, it is seen that flexural strength of testing groups, HE0735, HE1050 and HE0960 with increasing diameter and fiber length given in Table 5 were also increased to 5.50 MPa, 5.62 MPa and 6.70 MPa, respectively. In comparison with concrete samples without fibers, the strength results for HE0735, HE1050 and HE0960 testing sets were increased by $31.89 \%, 34.77 \%$ and $60.67 \%$ while the diameter and length of steel fibers were increased giving credence to the remarkable effect of aspect ratio (1/d) on flexural performance. Concerning the past research on the effect of fiber aspect ratio, the increase in flexural strength for higher aspect ratio can be attributed to the improvement in fracture energy of the fiber reinforced concrete (Balendran, Zhou, Nadeem \& Leung, 2002; Yazici, Inan \& Tabak, 2007).

The effect of macro synthetic fiber inclusion on flexural strength was also investigated through testing the specimen groups, EP and MM which resulted with improved flexural strengths of 5.26 MPa and 4.96 MPa, respectively. Among the specimens prepared with macro synthetic fibers, sample group, EP composed of sinusoidal shaped polyolefin fibers with smooth surface performed better with a strength improvement of $27.05 \%$ when compared with the latter group denoted as MM (with $19.81 \%$ increase in strength) which was produced from twisted bundle polypropylene fibers having a rough texture. Among the testing configurations with single fiber type as PP, steel and macro synthetic fibers, the influence of macro synthetic fibers on flexural performance was remarkable but less pronounced relative to steel fiber inclusion. Incorporation of steel fibers denoted with HE0960 having a fiber length of $60 \mathrm{~mm}$ attained the highest flexural strength improvement by $60.67 \%$ among the other sample configurations. Thus, it was observed that, besides the effects of fiber geometry, length and volume fraction, fiber type played an essential role in the mechanical behavior of cementitious composites. Figure 5 illustrates the fractured surface for the fiber reinforced concrete specimens after flexural strength test. 


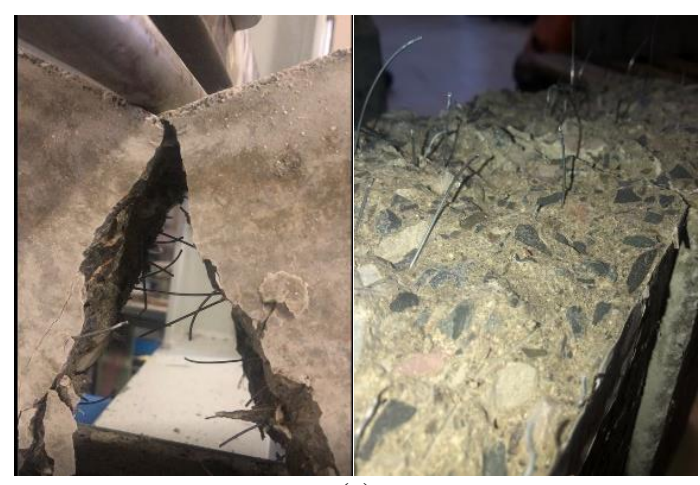

(a)

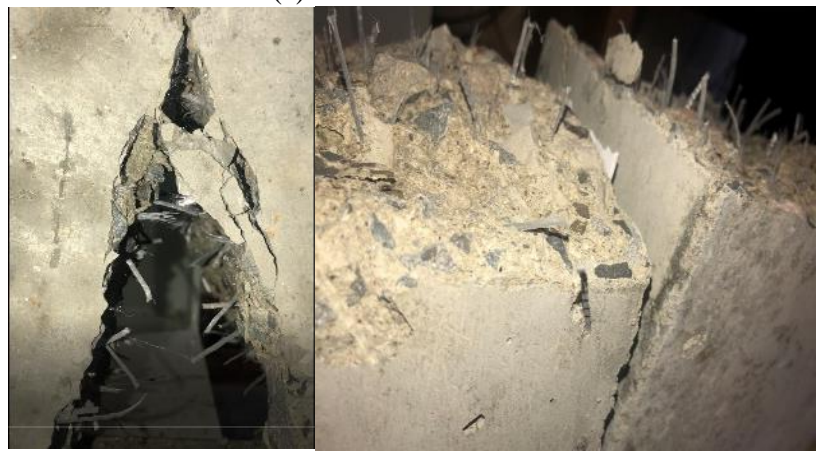

(c)

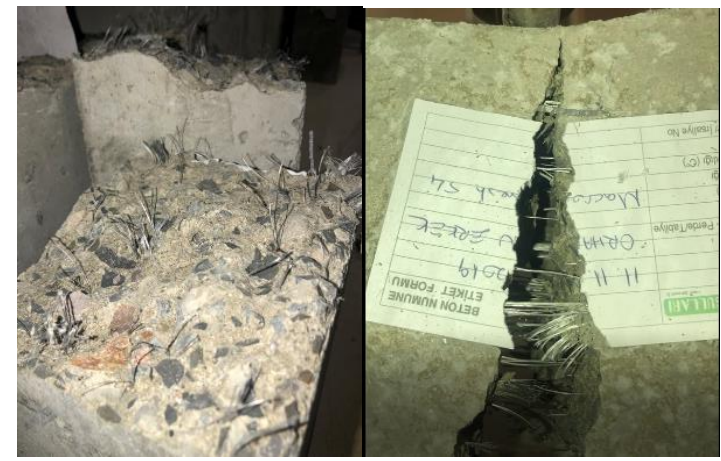

(b)

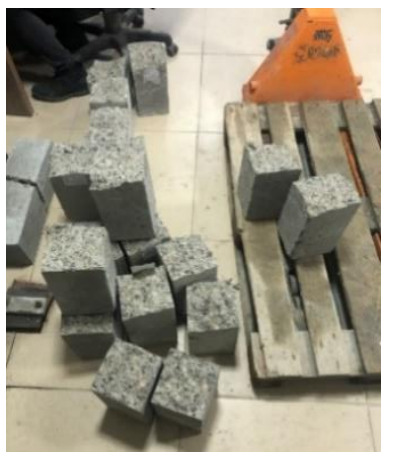

(d)

Figure 5. Flexural testing of fiber reinforced concrete specimens (a) steel fiber reinforced concrete; (b) macro synthetic fiber reinforced concrete (MM); (c) macro synthetic fiber reinforced concrete (EP); (d) control specimens.

The effect of blending different types of fibers within the concrete mixture was also investigated by combining PP fibers with macro synthetic fiber denoted as EP-BF12, and with steel fiber as HE0960-BF12. The flexural strength of concrete specimens, EP-BF12 and HE0960-BF12 with macro synthetic and steel fibers were obtained as 7.03 MPa and 7.41 MPa for which the non-fibrous concrete strength was 4.14 MPa. These test results indicate that the hybrid fiber reinforced concrete batches exhibited the highest flexural performance within the entire sample configurations which were found to be $69.81 \%$ (EP-BF12) and 78.99\% (HE0960-BF12) higher than the control mixture.

Clearly, hybridization of two different types of fibers provided an effective strengthening in the concrete matrix which might be attributed to the synergistic interaction between PP and steel fibers; and PP and macro synthetic fibers within the composition. According to the studies on the use of hybrid form of steel fibers, inclusion of micro fibers favorably reinforces the multiple microcracking behavior, thus leading to strain hardening, while macro fibers provide improvements in post cracking strength and strain capacity (Park, Kim, Ryu \& Koh, 2012). Other studies on blending effect of short and long steel fibers particularly underlined that short and thin fibers played a major role in bridging microcracks while longer fibers are effective in arresting macrocracks within the concrete matrix. Therefore, PP-steel hybrid form has been the most beneficial combination followed by blended configuration with PP-macro fibers in terms of flexural strength improvement which offers superior engineering properties through utilizing the potential aspects of each fiber type.

\section{Conclusions}

In this study, the effect of fiber type and incorporation of their hybrid forms in concrete was investigated through a comprehensive experimental study on compressive and flexural strength of fiber reinforced concrete prepared with three different types of fibers as PP, macro synthetic and steel fibers; and the hybrid use of PP with steel and with macro synthetic fibers. Considering the entire sample configurations, fiber inclusion in concrete was found to cause slight variations in compressive strength which was consistent with previous studies. However, the test results of flexural strength for all sample configurations were promising. The best flexural performance within the entire set of concrete mixes including single type of fibers as PP, 
macro synthetic and steel was ranked as $60.67 \%$ (HE0960), 42.45\% (BF19), 27.05\% (EP) of strength increase relative to nonfibrous concrete. The results also revealed that the concrete specimens incorporating steel fibers achieved the highest improvement in flexural strength. Moreover, it was clearly observed that the higher aspect ratio of steel fibers resulted in better flexural performance, among the steel fiber reinforced concrete specimens. Thus, it was concluded that the fiber length and diameter played a significant role on flexural performance of steel fiber reinforced concrete.

It was found that the fiber blending with combinations of PP-steel and PP-macro synthetic resulted in the highest flexural strength compared with single type of fiber inclusion as PP, steel and macro-synthetic fibers within the designated testing groups in this study. In hybrid forms, samples including PP with steel fibers (HE0960-BF12) and PP with macro synthetic fibers (EP-BF12) attained flexural strength increase of $69.81 \%$ and $78.99 \%$ which are higher than the control specimens, indicating the synergistic effect of fiber blending. These results obviously indicated that the fiber blending provides remarkable improvements in the mechanical performance of concrete and cementitious composites strengthening the fiber-matrix interaction.

By the incorporation of different type, content and size of fibers in concrete, significant improvements can be achieved in the overall performance of concrete and cementitious composites. The significance of this study lies in providing in-depth information on the mechanical performance of polypropylene, macro synthetic and steel fiber reinforced concrete by considering the fiber length, diameter and hybrid incorporation of fibers in concrete. Clear improvements in flexural strengths were obtained for all combinations of fiber reinforced concrete specimens prepared in this study, while the most promising results were achieved by incorporating the hybrid forms of polypropylene-steel and polypropylene-macro synthetic fibers in concrete, indicating the synergistic effect of fiber blending. It is believed that the findings of this comprehensive research might provide a comparative assessment of the tailored mechanical properties of fiber reinforced concrete and contribute to the growing body of literature on the use of fiber reinforced concrete as an efficient construction material.

\section{References}

Abbass, W., Khan, M. I. \& Mourad, S. (2018). Evaluation of mechanical properties of steel fiber reinforced concrete with different strengths of concrete. Construction and Building Materials, 168, 556-569. https://doi.org/10.1016/j.conbuildmat.2018.02.164

Akcay, B. (2012). Experimental investigation on uniaxial tensile strength of hybrid fibre concrete. Composites Part B: Engineering, 43(2), 766-778. https://doi.org/10.1016/j.compositesb.2011.08.017

ASTM A820/A820M-04 (2015). Standard specification for steel fibers for fiber-reinforced concrete. West Conshohocken, Pennsylvania: ASTM International.

Balendran, R. V., Zhou, F. P., Nadeem. A. \& Leung, A. Y. T. (2002). Influence of steel fibres on strength and ductility of normal and lightweight high strength concrete. Building and Environment, 37(12), 1361-1367. https://doi.org/10.1016/S0360-1323(01)00109-3

Banthia, N. \& Gupta, R. (2006). Influence of polypropylene fiber geometry on plastic shrinkage cracking in concrete. Cement and Concrete Research, 36(7), 1263-1267. https://doi.org/10.1016/j.cemconres.2006.01.010

Banthia, N. \& Nandakumar, N. (2003). Crack growth resistance of hybrid fiber reinforced cement composites. Cement and Concrete Composites, 25(1), 39. https://doi.org/10.1016/S0958-9465(01)00043-9

Banthia, N, \& Trottier, J. F. (1995). Concrete reinforced with deformed steel fibres. Part II: Toughness characterization. ACI Materials Journal, 92(2), 14654.

Bolat, H., Şimşek, O., Çullu, M., Durmuş, G. \& Can, Ö. (2014). The effects of macro synthetic fiber reinforcement use on physical and mechanical properties of concrete. Composites Part B: Engineering, 61, 191-198. https://doi.org/10.1016/j.compositesb.2014.01.043

Chousidis, N., Zacharopoulou, A. K. \& Batis, G. (2020). Corrosion protection of reinforcement steel using solid waste materials in concrete production. Magazine of Concrete Research, 72(6), 271-277. https://doi.org/10.1680/jmacr.17.00537

Grzybowski, M. \& Shah, S. P. (1990). Shrinkage cracking of fiber reinforced concrete. ACI Materials Journal, 87(2), 138-148.

Guerini, V., Conforti, A. \& Plizzari, G. (2018). Kawashima S. Influence of steel and macro-synthetic fibers on concrete properties. Fibers, 6(3), 1-14. https://doi.org/10.3390/fib6030047

Kakooei, S., Akil, H. M., Jamshidi, M. \& Rouhi, J. (2012). The effects of polypropylene fibers on the properties of reinforced concrete structures. Construction and Building Materials, 27(1), 73-77. https://doi.org/10.1016/j.conbuildmat.2011.08.015 
Karapınar, I. S. \& Biricik, H. (2020). Pozzolanic activity of central Anatolian volcanic tuff and its usability as admixture in mortar, Advances in Cement Research, 32(3), 91-100. https://doi.org/10.1680/jadcr.18.00033

Kavitha, S. M., Venkatesan, G., Avudaiappan, S. \& Flores, E. I. S. (2020). Mechanical and flexural performance of self compacting concrete with natural fiber, Revista de la Costruccion, 19(2), 370-380. https://doi.org/ 10.7764/RDLC.19.2.370

Kayali, O,, Haque, M. N. \& Zhu, B. (2003). Some characteristics of high strength fiber reinforced lightweight aggregate concrete. Cement and Concrete Composites, 25(2), 207-213. https://doi.org/10.1016/S0958-9465(02)00016-1

Kim, D. J., Park, S. H., Ryu, G. S. \& Koh, K. T. (2011). Comparative flexural behavior of Hybrid Ultra High Performance Fiber Reinforced Concrete with different macro fibers. Construction and Building Materials, 25(11), 4144-4155. https://doi.org/10.1016/j.conbuildmat.2011.04.051

Lee, N. K. \& Lee. H. K. (2013). Setting and mechanical properties of alkali-activated fly ash/slag concrete manufactured at room temperature, Construction and Building Materials, 74, 1201-1209. https://doi.org/10.1016/j.conbuildmat.2013.05.107

Malhotra, V. M. (2002). Introduction: sustainable development and concrete technology. ACI Concrete International, 24(7), 22.

Mehta, P. K. (2001). Reducing the environmental impact of concrete. ACI Concrete International, 23(10), 61-6.

Mobasher, B., Dey, V., Bauchmoyer, J., Mehere, H. \& Schaef, S. (2019). Reinforcing efficiency of micro and macro continuous polypropylene fibers in cementitious composites. Applied Sciences (Switzerland), 9(11), 2189. https://doi.org/10.3390/app9112189

Nath, P. \& Sarker. P. K. (2014). Effect of GGBFS on setting, workability and early strength properties of fly ash geopolymer concrete cured in ambient condition. Construction and Building Materials, 66, 163-171. https://doi.org/10.1016/j.conbuildmat.2014.05.080

Neville, A. M. (2011). Properties of concrete. 5th ed. Trans-Atlantic Publications.

Noushini, A., Samali, B. \& Vessalas, K. (2014). Static mechanical properties of polyvinyl alcohol fibre reinforced concrete (PVA-FRC). Magazine of Concrete Research, 66(9), 465-483. https://doi.org/10.1680/macr.13.00320

Park, S. H., Kim, D. J., Ryu, G. S. \& Koh, K. T. (2012). Tensile behavior of ultra high performance hybrid fiber reinforced concrete. Cement and Concrete Composites, 34(2), 172-184. https://doi.org/10.1016/j.cemconcomp.2011.09.009

Qian, C. X. \& Stroeven, P. (2000). Development of hybrid polypropylene-steel fiber- reinforced concrete. Cement and Concrete Research, 30(1), 63-69. https://doi.org/10.1016/S0008-8846(99)00202-1

Rapoport, J., Aldea, C., Shah, S. P., Ankenman, B. \& Karr, A. F. (2001). Permeability of Cracked Steel Fiber-Reinforced Concrete. Technical Report No.115, National Institute of Statistical Sciences(NISS), Research Triangle Park, NC, USA.

Sahin, Y. \& Koksal, F. (2011). The influences of matrix and steel fibre tensile strengths on the fracture energy of high-strength concrete. Construction and Building Materials, 25(4), 1801-1806. https://doi.org/10.1016/j.conbuildmat.2010.11.084

Sun, Z. \& Xu, Q. (2009). Microscopic, physical and mechanical analysis of polypropylene fiber reinforced concrete. Materials Science and Engineering: A, 527(1-2), 198-204. https://doi.org/10.1016/j.msea.2009.07.056

Tiberti, G., Minelli, F. \& Plizzari, G. (2015). Cracking behavior in reinforced concrete members with steel fibers: A comprehensive experimental study. Cement and Concrete Research, 68, 24-34. https://doi.org/10.1016/j.cemconres.2014.10.011

TS-10515 (1992). Concrete-Steel Fibre Reinforced-Test Method for Flexural Toughness. Turkish Standards Institute. Ankara.

TS-706-EN-12620 (2003). Aggregates for Concrete. Turkish Standards Institute. Ankara.

TS-EN-12390-3 (2003). Testing Hardened Concrete - Part 3: Compressive Strength of Test Specimens. Turkish Standards Institute. Ankara.

TS-EN-12390-5 (2002). Testing hardened concrete - Part 5: Flexural strength of test specimens. Turkish Standards Institute. Ankara.

TS-EN-197-1 (2002). Cement- Part 1: Compositions and conformity criteria for common cements. Turkish Standards Institute. Ankara.

Yao, W., Li, J. \& Wu, K. (2003). Mechanical properties of hybrid fiber-reinforced concrete at low fiber volume fraction. Cement and Concrete Research, 33(1), 27-30. https://doi.org/10.1016/S0008-8846(02)00913-4

Yazici, S., Inan, G. \& Tabak, V. (2007). Effect of aspect ratio and volume fraction of steel fiber on the mechanical properties of SFRC. Construction and Building Materials, 21(6), 1250-1253. https://doi.org/10.1016/j.conbuildmat.2006.05.025

Yoo, D. Y., Yoon, Y. S. \& Banthia, N. (2015). Flexural response of steel-fiber-reinforced concrete beams: Effects of strength, fiber content, and strain-rate. Cement and Concrete Composites, 64, 84-92. https://doi.org/10.1016/j.cemconcomp.2015.10.001 